\title{
Impaired glucose tolerance precedes but does not predict insulin-dependent diabetes mellitus: a study of identical twins
}

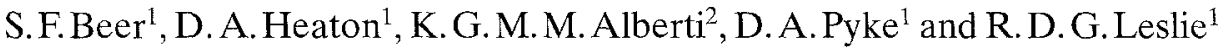 \\ ${ }^{1}$ Department of Medicine and Diabetes, King's College Hospital, London, and \\ ${ }^{2}$ Department of Medicine, University of Newcastle-upon-Tyne, Newcastle-upon-Tyne, UK
}

\begin{abstract}
Summary. Non-diabetic identical twins of insulin-dependent diabetic patients were studied within five years of the diagnosis of their index twin in order to determine whether changes in intermediary metabolism precede the onset of insulin-dependent diabetes mellitus. Two studies were performed: a cross-sectional study of 12 non-diabetic twins and a prospective study of a separate group of 41 non-diabetic twins. Of the 12 twins tested in the cross-sectional study six developed insulin-dependent diabetes and six did not; the six who developed diabetes were given an oral glucose load a mean of 10 months before diagnosis; they then had normal fasting blood glucose levels but worse glucose tolerance than control subjects (120 min post-load (mean \pm SD) blood glucose $8.5 \pm 3.5$ vs $4.9 \pm 0.9 \mathrm{mmol} / \mathrm{l}$ respectively, $p<0.05$ ). However, blood lactate, pyruvate, alanine, glycerol, 3-hydroxybutyrate and serum insulin levels were similar. In contrast, the six twins in this cross-sectional study who did not develop diabetes and are now unlikely to do so, as a group, had no significant changes compared with the control subjects though one had impaired glucose tolerance. To determine the predic-
\end{abstract}

tive value of impaired glucose tolerance a separate group of 41 non-diabetic twins was studied prospectively for 8 to 22 years having a total of 147 glucose tolerance tests in this period; in this group six developed diabetes. Eight of the 41 had impaired glucose tolerance; impaired glucose tolerance was found in four of the six who developed diabetes as compared with only four of the 35 who did not $(p<0.01)$. Impaired glucose tolerance in these non-diabetic identical twins had a positive predictive value of $33 \%$ for developing diabetes. The four twins with impaired glucose tolerance who remain nondiabetic now have normal glucose tolerance. We conclude that impaired glucose tolerance may precede the onset of insulin-dependent diabetes mellitus by many months but the change does not specifically predict the disease even in identical twins of diabetic patients. These observations are consistent with the possibility that in some twins the disease process can occur yet remit without leading to diabetes.

Key words: Impaired glucose tolerance, pre-diabetes, insulin-dependent diabetes, identical twins, metabolism.
Insulin-dependent diabetes mellitus is due to destruction of the insulin secreting Beta cells of the pancreas. The clinical onset of the disease may be rapid although islet cell antibodies [1] and impaired glucose tolerance can occur some months to years before diagnosis [2-5]. These observations suggest that clinical diabetes is preceded by detectable metabolic changes presumably due to Beta cell dysfunction. Minor Beta cell dysfunction can be associated with extensive changes in intermediary metabolism other than glucose; such changes have been found in nondiabetic identical twins and children of non-insulin-dependent diabetic patients both of whom were at high risk of developing diabetes [6,7]. Similar changes in intermediary metabolism could occur in twins at risk of insulin-dependent diabetes mellitus. We therefore studied non-diabetic identical twins of recently diagnosed insulin- dependent diabetic patients to determine whether changes in intermediary metabolism preceded the onset of the disease and if so, whether such changes were pathognomonic.

\section{Subjects and methods}

\section{Patients}

Non-diabetic identical twins of insulin-dependent diabetic patients were selected who had an oral glucose tolerance test first performed within five years of the diagnosis of diabetes in their index twin. Monozygosity was established in all the twin pairs as previously described $[8,9]$. Subjects or parents gave informed consent and the study was approved by the King's College Hospital Ethical Committee. At the time of the initial test none of the subjects had previously 
Table 1. Mean ( \pm SD) concentrations for metabolites when fasting and 60 and 120 min after oral glucose in pre-diabetic twins and their control subjects and non-diabetic twins and their control subjects

\begin{tabular}{|c|c|c|c|c|}
\hline & $\begin{array}{l}\text { Pre-diabetic } \\
\text { Twins }\end{array}$ & $\begin{array}{l}\text { Control } \\
\text { subjects }\end{array}$ & $\begin{array}{l}\text { Non-diabetic } \\
\text { Twins }\end{array}$ & $\begin{array}{l}\text { Control } \\
\text { subjects }\end{array}$ \\
\hline \multicolumn{5}{|c|}{ Lactate (mmol/l) } \\
\hline \multicolumn{5}{|c|}{ Pyruvate (mmol/l) } \\
\hline \multicolumn{5}{|c|}{ Glycerol (mmol/l) } \\
\hline $\begin{array}{l}\text { Fasting } \\
60 \mathrm{~min} \\
120 \mathrm{~min}\end{array}$ & $\begin{array}{l}0.025 \pm 0.021 \\
0.017 \pm 0.009 \\
0.016 \pm 0.010\end{array}$ & $\begin{array}{l}0.046 \pm 0.028 \\
0.042 \pm 0.028 \\
0.042 \pm 0.028\end{array}$ & $\begin{array}{l}0.048 \pm 0.038 \\
0.048 \pm 0.041 \\
0.052 \pm 0.050\end{array}$ & $\begin{array}{l}0.042 \pm 0.030 \\
0.036 \pm 0.031 \\
0.037 \pm 0.031\end{array}$ \\
\hline \multicolumn{5}{|c|}{ 3-Hydroxybutyrate (mmol/l) } \\
\hline $\begin{array}{l}\text { Fasting } \\
60 \mathrm{~min} \\
120 \mathrm{~min}\end{array}$ & $\begin{array}{c}0.05 \pm 0.05 \\
0.009 \pm 0.004 \\
0.006 \pm 0.004\end{array}$ & $\begin{array}{l}0.04 \pm 0.02 \\
0.009 \pm 0.008 \\
0.005 \pm 0.006\end{array}$ & $\begin{array}{c}0.09 \pm 0.07 \\
0.002 \pm 0.006 \\
0.002 \pm 0.004\end{array}$ & $\begin{array}{c}0.05 \pm 0.03 \\
0.009 \pm 0.008 \\
0.005 \pm 0.005\end{array}$ \\
\hline
\end{tabular}

had a glucose tolerance test; none was clinically ill, taking any drugs and all of them were eating their usual diet at the time of the tests. Two separate studies were performed on separate cohorts of twins both of whom fulfilled the criteria for entry set out above. The first study was cross-sectional using a $75 \mathrm{~g}$ glucose load in which we sought changes in insulin, glucose and other intermediate metabolites in the non-diabetic twins. The second study was prospective using a $50 \mathrm{~g}$ glucose load and assessing only glucose in the nondiabetic twins.

\section{Study 1}

A consecutive series of 12 non-diabetic twins was tested on a single occasion between 1983 and 1985 with a $75 \mathrm{~g}$ (or $1.75 \mathrm{~g} / \mathrm{kg}$ whichever was the less) oral glucose load. Six of the twins subsequently developed diabetes (these twins can be designated prediabetic twins), they were tested a mean of 10 months (range 3 to 18) before diagnosis; mean ( \pm SD) age $15.3 \pm 5.5$ years (range $11-25$ ), body mass index (BMI) $17.8 \pm 3.8 \mathrm{~kg} / \mathrm{m}^{2}$ (range 16-22); three were male. As required by the criteria of entry all the twins were within five years of the diagnosis of their index twin (median 7 months range 1 to 24). They were compared with seven control subjects of similar age (15.6 \pm 4.0 years; range $10-24), \mathrm{BMI}\left(20.2 \pm 3.4 \mathrm{~kg} / \mathrm{m}^{2}\right.$; range $\left.16-25\right)$ and sex (four male). The remaining six twins are still not diabetic seven to 10 years from the diagnosis of the index twin; their mean age at testing was $16.9 \pm 3.9$ years (range $14-24$ ), BMI of $22.6 \pm 3.7 \mathrm{~kg} / \mathrm{m}^{2}$ (range 20-29), four were male. They were compared with seven control subjects of similar age, (16.7 \pm 3.9 years; range $13-24)$, BMI $\left(20.7 \pm 3.8 \mathrm{~kg} / \mathrm{m}^{2}\right.$; range $\left.17-26\right)$ and sex (three male). Control subjects were sought from unrelated members of families in the local community known to families with diabetic children. These control subjects were not attached to the hospital, had no family history of diabetes, were taking no drugs, had no clinical signs or symptoms of illness and were eating their normal diet at the time of testing; individual matching was not performed, the control subjects were selected to achieve a similar distribution for age, sex and body mass index to the twin groups.

\section{Study 2}

A consecutive series of 41 non-diabetic twins were first tested between 1967 to 1981 with $50 \mathrm{~g}$ (or $1.75 \mathrm{~g} / \mathrm{kg}$ whichever was the less) oral glucose load; these twins were a separate group from those tested in Study 1. Of 41 twins studied 6 developed diabetes while the remainder are not diabetic at least eight years from the diagnosis of the index twin. These 41 twins (mean age when first tested $19 \pm 11$ years; 17 male) had glucose tolerance tests on 147 occasions (median 3 per twin, range 1-8 tests). The first glucose test was performed within five years of the diagnosis of the index twin but subsequent tests were performed at intervals which were not standardised. As required by the criteria of entry all the twins were within five years of the diagnosis of their index twin (median 16 months range 1 to 46 ).

\section{Methods}

Subjects were studied after an overnight fast (10-12 h); after $30 \mathrm{~min}$ rest basal venous blood samples were taken at -10 and 0 min before $75 \mathrm{~g}$ glucose (for Study 1) or $50 \mathrm{~g}$ (for Study 2) or $1.75 \mathrm{~g} / \mathrm{kg}$ (whichever was the less) dissolved in 0.331 of water and consumed over $4 \mathrm{~min}$. The change in glucose load was made in line with the recommendations of the National Diabetes Data Group [10]. Further samples of venous blood were taken at $10 \mathrm{~min}$ for Study 1 and for both studies at 30,60,90 and $120 \mathrm{~min}$. Whole blood glucose was analysed by a glucose oxidase method (Yellow Springs Analyser) for Study 1 and by autoanalyser using the potassium ferricyanide method for Study 2. Standards and quality controls give virtually identical results with both methods as previously reported [10].

Serum insulin was measured by a double antibody radioimmunoassay [11]. A perchlorate extract of whole blood was assayed for lactate, pyruvate, alanine, glycerol and 3-hydroxybutyrate concentrations by an automated fluorometric technique [12].

Twins with diabetic symptoms were excluded from the study as this was a study of non-diabetic twins. Diabetes, in the remainder, was diagnosed according to the National Diabetes Data Group crite- 
Table 2. Mean ( \pm SD) concentrations for glucose and insulin when fasting and 60 and 120 min after oral glucose in pre-diabetic twins and their control subjects and non-diabetic twins and their control subjects. ${ }^{a}$ Differences significant at $p<0.05$

\begin{tabular}{|c|c|c|c|c|}
\hline & $\begin{array}{l}\text { Pre-diabetic } \\
\text { Twins }\end{array}$ & $\begin{array}{l}\text { Control } \\
\text { subjects }\end{array}$ & $\begin{array}{l}\text { Non-diabetic } \\
\text { Twins }\end{array}$ & $\begin{array}{l}\text { Control } \\
\text { subjects }\end{array}$ \\
\hline \multicolumn{5}{|c|}{ Glucose $(\mathrm{mmol} / \mathrm{l})$} \\
\hline \multicolumn{5}{|c|}{ Insulin (pmol/l) } \\
\hline $\begin{array}{l}60 \text { min } \\
\text { Range }\end{array}$ & $\begin{array}{l}235 \pm 56 \\
155-309\end{array}$ & $\begin{array}{l}208 \pm 42 \\
163-270\end{array}$ & $\begin{array}{l}357 \pm 373 \\
117-1155\end{array}$ & $\begin{array}{l}236 \pm 61 \\
175-365\end{array}$ \\
\hline $\begin{array}{l}120 \text { min } \\
\text { Range }\end{array}$ & $\begin{array}{l}180 \pm 113 \\
108-393\end{array}$ & $\begin{array}{l}158 \pm 29 \\
125-204\end{array}$ & $\begin{array}{r}285 \pm 336 \\
89-807\end{array}$ & $\begin{array}{l}174 \pm 45 \\
125-266\end{array}$ \\
\hline
\end{tabular}

ria [10], i.e. when the twins had either: (1) a whole blood glucose level of $6.7 \mathrm{mmol} / \mathrm{l}$ or more when fasting and of $10 \mathrm{mmol} / 1$ or more $2 \mathrm{~h}$ after oral glucose, or (2) a whole blood glucose less than $6.7 \mathrm{mmol} / 1$ when fasting and equal to or greater than $10.0 \mathrm{mmol} / 1$ both at $2 \mathrm{~h}$ and one other earlier blood sample following oral glucose. Normal glucose levels were defined as whole blood glucose when fasting less than $5.6 \mathrm{mmol} / \mathrm{l}$ (for adults) and less than $6.4 \mathrm{mmol} / 1$ (for children), and after oral glucose, levels less than $6.7 \mathrm{mmol} / \mathrm{l}$ at $2 \mathrm{~h}[10]$.

\section{Islet cell antibody determination}

Undiluted sera from twins were screened for islet cell antibodies (ICA) by an indirect immunofluorescence technique by using sections of blood group 0 human pancreas [13]. With the same pancreas, reagents and incubation conditions, the putative ICA standard ( 80 Juvenile Diabetes Federation units) currently being assessed by the Immunology and Diabetes Workshops gave endpoint titres of 32 when tested "blind" on two occasions. Samples were read "blind" by two independent observers. The results are presented as positive or negative with positive tests being greater than 10 units. All the twins in Study 1 were tested for ICA at the time of the study. The twins in Study 2 were not systematically tested for ICA as sera is no longer available in all of them, any twin who showed impaired glucose tolerance and remained non-diabetic was retested for ICA.

\section{Predictive value}

To calculate the predictive value of a test it is necessary to know with a degree of certainty the positive and negative chances of developing the disease. We estimate that the twins who remain non-diabetic in Study 1 and Study 2 now have less than a $1 \%$ risk of developing diabetes $[9,14]$. To assess impaired glucose tolerance as a predictor of insulin-dependent diabetes we estimated (a) its positive predictive value by calculating the number of twins in whom impaired glucose tolerance was detected and later developed insulin-dependent diabetes mellitus as a percentage of the overall number of twins who showed impaired glucose tolerance; (b) its sensitivity by dividing the number of twins with it who later developed diabetes mellitus by the overall number of twins who developed diabetes mellitus; and (c) its specificity by dividing the number of twins who did not show it and did not develop insulin-dependent diabetes mellitus by the total number of twins who did not develop diabetes. Similar estimates were made for elevated levels of fasting blood glucose. As changes in glucose tolerance are unlikely to be static the calculated predictive value may be dependent on the frequency or timing of tests per- formed. In addition, the number of twins in Study 1 is very small. We therefore analysed only the first glucose test performed on each nondiabetic twin in Study 2.

\section{Statistical analysis}

Results are expressed as the mean and standard deviation ( \pm SD) of the mean. The significant variables approximated to a normal distribution in that $66 \%$ of the values fell within one SD of their mean unless stated. Changes were compared using a two-tailed Student's t-test for unpaired observations, Wilcoxon's rank sum test and Chi squared; differences were considered significant at $p<0.05$ ).

\section{Results}

\section{Study 1}

Fasting concentrations. There was no difference in fasting glucose, insulin, lactate, pyruvate, glycerol, alanine, and 3hydroxybutyrate compared to control subjects in either the pre-diabetic group or the group of twins who did not develop diabetes (Tables 1 and 2). None of the twins had fasting glucose levels greater than $5.6 \mathrm{mmol} / 1$. The fasting insulin/glucose $(\mathrm{pmol} / \mathrm{mmol}$ ) ratio in the group of prediabetic twins (3.5 \pm 2.1$)$ and non-diabetic twins (mean 2.9 range 1.3 to 6.9 ) was not significantly different from control values ( $1.9 \pm 0.6$ and $2.0 \pm 0.6$ respectively).

Response to oral glucose. After oral glucose the prediabetic twins had significantly worse glucose tolerance than the control subjects at 30, 90, and 120 min (Fig. 1). The twins who remain non-diabetic did not show any significant difference compared with their control subjects. In neither the pre-diabetic nor the non-diabetic group was there any significant difference in insulin, lactate, pyruvate, glycerol, alanine, or 3-hydroxybutyrate compared with the control subjects when expressed as levels at any time (Table 1). The mean insulin $/$ glucose $(\mathrm{pmol} / \mathrm{mmol})$ ratio did not differ significantly in the group of prediabetic twins as compared with their control subjects at $60 \mathrm{~min}(3.0 \pm 1.0$ vs $5.7 \pm 2.3$ respectively) or at $120 \mathrm{~min}$ $(3.4 \pm 1.4$ vs $4.9 \pm 1.8$ respectively) nor did it differ signifi- 


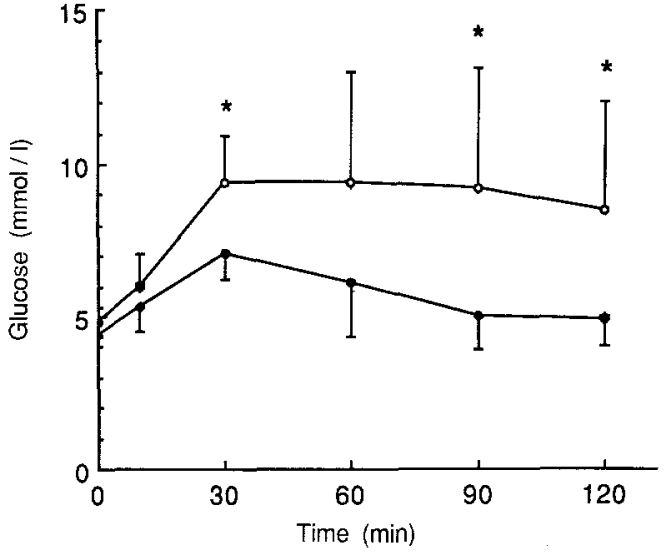

Fig. 1. Mean ( \pm SD) glucose levels following oral glucose load in six pre-diabetic twins $(\mathrm{O}-\mathrm{O})$ and seven control subjects $(\bullet-)$ in Study $1{ }^{*} p<0.05$

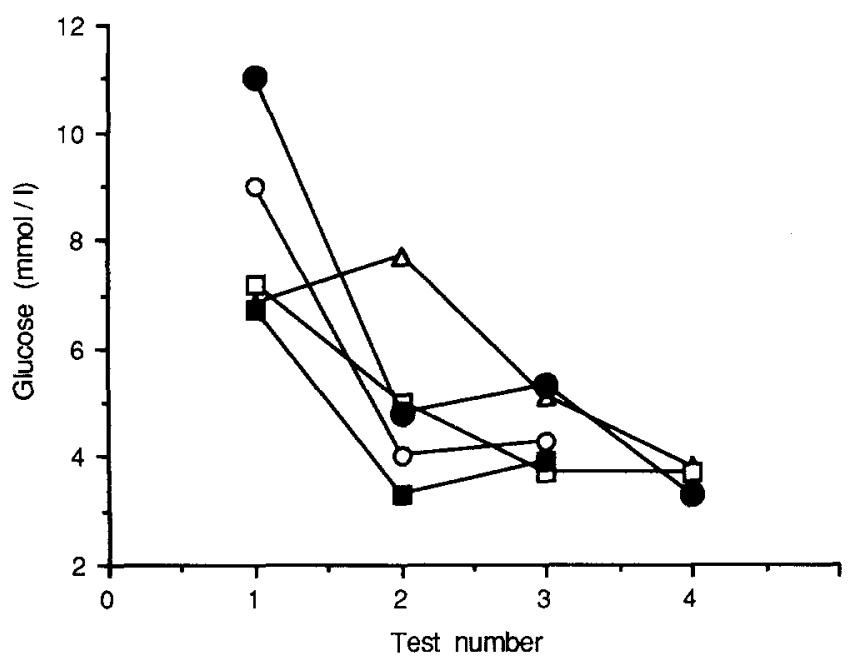

Fig. 2. Venous whole blood glucose $120 \mathrm{~min}$ after an oral glucose tolerance test in five non-diabetic identical twins of insulin-dependent diabetic patients from Study 1 (one twin) and Study 2 (four twins). The first test was done within five years of the diagnosis of the index twin; the interval between subsequent tests was variable. All five twins had impaired glucose tolerance which became normal and they are now unlikely to develop diabetes. $-\triangle$ Twin $1 ;-0$ Twin $2 ;-\square-$ Twin $3 ; \longrightarrow$ Twin $4 ; \multimap-$ Twin 5

cantly in the twins who remain non-diabetic as compared with their control subjects at $60 \mathrm{~min}(7.3 \pm 2.4$ vs $5.0 \pm 2.0$ respectively) or at $120 \mathrm{~min}(7.1 \pm 2.3$ vs $5.1 \pm 2.1$ respectively).

Impaired glucose tolerance was found in three of the six pre-diabetic twins and in one of the six twins who remain non-diabetic. This one non-diabetic twin with impaired glucose tolerance now has normal glucose tolerance (Fig. 2). The mean blood glucose level $2 \mathrm{~h}$ after oral glucose was also higher $(6.5 \mathrm{~mol} / \mathrm{l})$ in the three prediabetic twins without impaired glucose tolerance than in control subjects $(4.9 \mathrm{mmol} / \mathrm{l})$. Of the three pre-diabetic twins found to have impaired glucose tolerance two had glucose levels greater than $10 \mathrm{mmol} / 12 \mathrm{~h}$ after the glucose load though neither fulfilled the criteria for diabetes [10]. One of these pre-diabetic twins subsequently had normal glucose tolerance before developing diabetes after
18 months, the other twins developed diabetes 2 and 14 months later.

All six pre-diabetic twins had ICA at the time of study, in all cases at titres greater than 20 JDF units, while none of the twins who remained non-diabetic had these antibodies including the twin with impaired glucose tolerance.

\section{Study 2}

Of the separate group of 41 non-diabetic identical twins of recently diagnosed insulin-dependent diabetic patients six have developed insulin-dependent diabetes. Eight twins had impaired glucose tolerance, four have since developed diabetes and four remain non-diabetic demonstrating a significant tendency for these twins with impaired glucose tolerance to develop diabetes $(p<0.01)$. This difference occurred despite the non-diabetic twins having more tests on average (3.7) than the twins who became diabetic (2.7). Impaired glucose tolerance was found in four of the 16 tests performed in twins who became diabetic and five of the 131 tests performed in twins who remain non-diabetic; a significant difference $(p<0.01)$. Impaired glucose tolerance was first detected in all the pre-diabetic twins within five years of the diagnosis of the index twin and 141, 39, 20 and 9 months before their diagnosis of diabetes (Fig. 2). Of the 35 twins who remain nondiabetic, four had impaired glucose tolerance and then only within five years of the diagnosis of the index twin but not thereafter (Fig. 2). This tendency to have impaired glucose tolerance close to the diagnosis of the index twin was significant; of the 35 twins who remain non-diabetic four had impaired glucose tolerance when first tested within five years of the diagnosis of the index twin as compared with none of them first tested after five years from the diagnosis of the index twin $(p<0.05)$. All four twins with impaired glucose tolerance now have normal glucose tolerance at 8,9,10 and 23 years from the onset of diabetes in the index twin. Only one of the four twins who remain non-diabetic showed impaired glucose tolerance on two occasions (two years apart) before the test became normal. In one of these four twins the glucose levels $2 \mathrm{~h}$ after a glucose load was greater than $10 \mathrm{mmol} / \mathrm{l}$ on a single occasion (Fig. 3) and yet she reverted to normal glucose tolerance and remains non-diabetic 10 years after the diagnosis of the index twin. None of the twins were found to have increased fasting glucose levels at the time of the last test before they became diabetic.

Islet cell antibodies were sought in the four twins who had transient impaired glucose tolerance and remain nondiabetic. None of these twins has ICA at present and in one twin from whom serum was available ICA was not detected when he had impaired glucose tolerance.

In this cohort of twins impaired glucose tolerance as a predictor of insulin-dependent diabetes mellitus had a sensitivity of $33 \%$, a specificity of $89 \%$ and a positive predictive value of $33 \%$. The fasting blood glucose remained normal so that no calculations could be made for the sensitivity, specificity or predictive value of an increased level. 


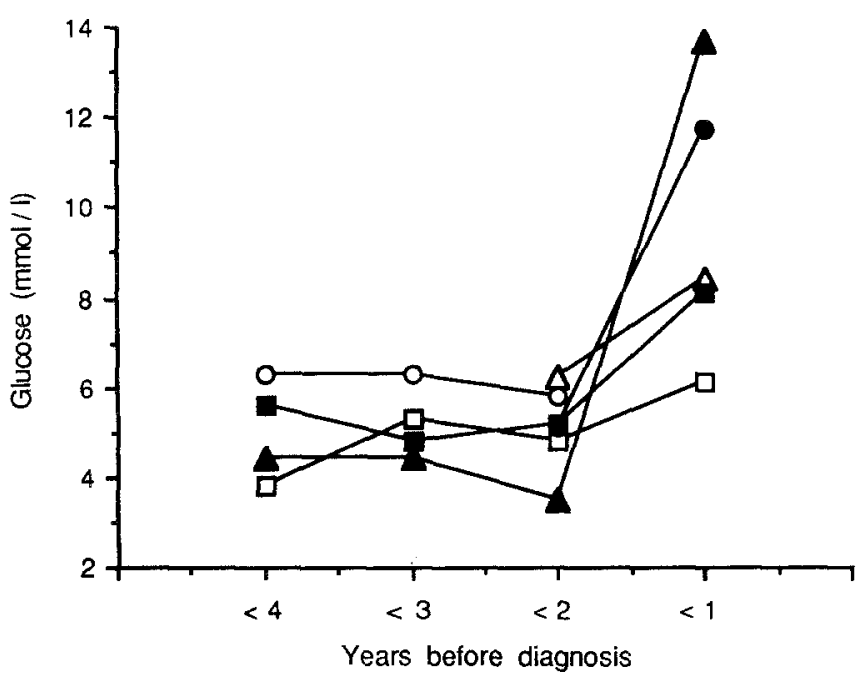

Fig.3. Venous whole blood glucose $120 \mathrm{~min}$ after an oral glucose tolerance test in six non-diabetic identical twins of insulin-dependent diabetic patients from Study 2 who subsequently developed diabetes themselves. The tests were all performed less than four years before their diagnosis of diabetes. $\triangle-$ Twin $1 ;-0$ Twin $2 ;-\square-$ Twin $3 ; \rightarrow$ Twin $4,-\square$ Twin $5 ;-$ Twin 6

\section{Discussion}

We have demonstrated impairment of glucose tolerance in pre-diabetic identical twins many months before they developed diabetes and before any changes in fasting glucose. In a cross-sectional study (Study 1) changes in glucose tolerance occurred without changes in other intermediary metabolites or insulin. This contrasts with studies of non-diabetic patients at risk of non-insulin-dependent diabetes which showed that these patients can have changes in both glucose and intermediary metabolites $[6$, 7]. The twins who remain non-diabetic did not, as a group, show any changes in either intermediary metabolites or insulin levels; one of these twins from Study 1 had impaired glucose tolerance. In Study 1 islet cell antibodies were found in all the pre-diabetic twins but in none of the twins who remain non-diabetic. These results raised the possibility that abnormal glucose tolerance could predict diabetes in individuals genetically at risk of the disease.

To test this hypothesis we analysed a prospective study of a separate group of non-diabetic identical twins of patients with insulin-dependent diabetes (Study 2). This prospective study confirmed that impaired glucose tolerance preceded changes in fasting glucose in four of six twins who subsequently developed the disease. Impaired glucose tolerance was associated with a significant tendency to progress to diabetes. However, some twins with impaired glucose tolerance did not develop diabetes and their glucose tolerance returned to normal; the positive predictive value of impaired glucose tolerance was $33 \%$. Within the limits of the definition of impaired glucose tolerance it was not possible to predict whether an individual would progress to diabetes. Two twins reverted to normal glucose tolerance despite having glucose levels greater than $10 \mathrm{mmol} / \mathrm{l}$ at $2 \mathrm{~h}$ after a glucose load; one remains non-diabetic with normal glucose tolerance
10 years after the diagnosis of the index twin while the other developed diabetes 18 months later. In this study these twins were designated as having impaired glucose tolerance as their glucose tolerance was neither frankly diabetic nor normal. It might be argued that these twins had diabetes according to some criteria and that the diabetes was transient [15]. At present, it is not possible to categorise these twins with certainty, though in the context of the present study this problem is semantic and serves only to emphasise the difficulty in designating genetically susceptible individuals as "pre-diabetic" until they have developed clinical diabetes.

Most previous studies of metabolic changes in prediabetic patients have been performed on relatives of patients with an undefined type of diabetes [16]. At least four groups have reported metabolic changes before the onset of insulin-dependent diabetes mellitus [3, 5, 17]; these changes include impaired glucose tolerance and a decreased insulin response to both oral and intravenous glucose. The sequence and prevalence of these metabolic changes has not been assessed since cohort studies of prediabetic subjects and suitable control subjects have not been reported. Impaired glucose tolerance in this present study had some predictive value though it is likely that other tests, such as ICA are better predictors of diabetes [14]. The predictive value of impaired glucose tolerance we report here must be regarded cautiously since it is derived from small numbers and only relates to subjects genetically susceptible to insulin-dependent diabetes mellitus such as these twins [8]. It remains possible that more frequent testing might have identified impaired glucose tolerance in all the twins during the pre-diabetic period.

Only one previous study has considered the predictive value of metabolic changes in subjects at risk of insulin-dependent diabetes mellitus [3]. It can be inferred from that study of siblings of insulin-dependent diabetic patients, though the authors do not comment on this aspect of their data, that impaired glucose tolerance did not predict diabetes with certainty since most of the siblings with impaired glucose tolerance remained non-diabetic after 10 years follow-up [3]. However, the risk of those nondiabetic siblings subsequently developing diabetes cannot be estimated from that paper [3]. In contrast to family studies, it is possible in diabetic twin studies to identify non-diabetic subjects who are genetically susceptible to the disease through both HLA and, probably, non-HLA genes yet have a very low risk of developing diabetes $[8,9$, 14]. This has enabled us to note that changes in proinsulin, activated T-lymphocytes and islet cell antibodies can occur in twins who are now unlikely to develop diabetes $[14,18,19]$. The present study extends these observations to include impaired glucose tolerance as a change which does not necessarily predict diabetes.

The striking difference in the number of twins who developed diabetes in Study 1 (6 of 12) as compared with those twins who developed diabetes in Study 2 (6 of 41) is probably due to the twins in Study 1 being referred earlier and being younger than those in Study 2; both factors being associated with increased concordance rates [9].

It is unlikely that all five twins with impaired glucose tolerance described in Study 1 and Study 2 will develop 
diabetes, as we calculate by both actuarial analysis and their lack of islet cell antibodies that the risk of these twins developing insulin-dependent diabetes is less than $1 \%[9$, 14]. The question arises as to whether the changes in glucose metabolism are associated with a remitting disease process or are non-specific. It is likely that the changes are specific since: (1) the frequency of impaired glucose tolerance in twins who remain non-diabetic is high $(11 \%)$, considerably higher than could be expected for a normal population of this age (about $2 \%$ ) [20] and (2) impaired glucose tolerance was only found in twins within five years of the diagnosis of the index twin. This clustering of changes in glucose tolerance around the time of diagnosis of the index twin suggests that the changes are not a nonspecific consequence of the potential variability in glucose tolerance [21]. Thus, some twins who remain non-diabetic showed both immune [19] and metabolic changes around the time of diagnosis of diabetes in the index twin but not thereafter. We conclude that a process which in some twins is associated with complete destruction of the insulin secreting Beta cells can, in others, remit spontaneously without leading to diabetes.

Acknowledgments. This study has been supported by the Medical Research Council, British Diabetic Association, Novo Ltd and the Nuffield Foundation. RDGL is supported by the Wellcome Trust. We are grateful to Dr. G.F.Bottazzo, Middlesex Hospital, London, for the estimation of islet cell antibodies. We are indebted to the following physicians who have studied our diabetic identical twin pairs: Drs. R.B.Tattersall, J.Cassar, P.G. Nelson, C. Theophanides, A.H.Barnett, C.Johnston, P.J.Hoskin and B.A.Millward. We thank Dr. Hodson, Ms. L. Ashworth and the staff of the Departments of Medicine and Clinical Biochemistry, Royal Victoria Infirmary, and University of Newcastle upon Tyne for help with assays of intermediary metabolites.

\section{References}

1. Srikanta S, Ganda OP, Jackson RA, Gleason RE, Kaldany A, Garovoy MR, Carpenter CB, Soeldner JS, Eisenbarth GS (1983) Type 1 diabetes mellitus in monozygotic twins: chronic progressive beta cell dysfunction. Ann Int Med 99: 320-326

2. Alviggi L, Johnston C, Hoskins PJ, Tee DEH, Pyke DA, Leslie RDG, Vergani D (1984) Pathogenesis of insulin dependent diabetes: a role for activated T-lymphocytes. Lancet II: 4-6

3. Rosenbloom AL, Hunt SS, Rosenbloom EK, MacLaren NK (1982) Ten-year prognosis of impaired glucose tolerance in siblings of patients with insulin-dependent diabetes. Diabetes 31 : 385-387

4. Ginsberg-Fellner F, Witt ME, Franklin BH, Yagihashi S, Toguchi Y, Dobersen MJ, Rubinstein P, Notkins Al (1985) Triad of markers for identifying children at high risk of developing insulin-dependent diabetes mellitus. JAMA 254: 1469-1472

5. Tarn AC, Smith CP, Spencer KM, Bottazzo GF, Gale EAM (1985) Type 1 (insulin dependent) diabetes: a disease of slow clinical onset. Br Med J 294: 342-345
6. Barnett AH, Spiliopoulos AJ, Pyke DA, Stubbs WA, Burrin J, Alberti KGMM (1981) Metabolic studies in unaffected co-twins of non-insulin dependent diabetics. Br Med J 282: 1656-1658

7. Leslie RDG, Volkmann HP, Poncher M, Hanning I, Oskov H, Alberti KGMM (1986) Metabolic abnormalities in children of non-insulin dependent diabetics. Br Med J 293: 840-842

8. Barnett AH, Eff C, Leslie RDG, Pyke DA (1981) Diabetes in identical twins. A study of 200 pairs. Diabetologia 20: $87-93$

9. Olmos P, A'Hern R, Heaton DA, Millward BA, Risley D, Pyke DA, Leslie RDG (1988) the significance of the concordance rate for Type 1 (insulin-dependent) diabetes in identical twins. Diabetologia 31: 747-750

10. National Diabetes Data Group (1979) Classification and diagnosis of diabetes mellitus and other categories of glucose intolerance. Diabetes 28: 1039-1057

11. Soeldner J, Slone D (1965) Critical variables in radioimmunoassay of serum insulin using the double antibody technic. Diabetes 14: 771-779

12. Lloyd B, Burrin J, Smythe P, Alberti KGMM (1978) Enzymatic fluorometric continuous-flow assay for blood glucose, lactate, pyruvate, alanine, glycerol and 3-hydroxybutyrate. Clin Chem 24: $1724-1729$

13. Tarn AC, Thomas JM, Dean BM, Ingram D, Schwarz G, Bottazzo GF, Gale EAM (1988) Predicting insulin-dependent diabetes. Lancet I: $845-850$

14. Johnston C, Millward BA, Hoskins P, Leslie RDG, Bottazzo GF, Pyke DA (1989) Islet cell antibodies as predictors of the later development of Type 1 (insulin-dependent) diabetes. Diabetologia 32: $382-386$

15. World Health Organisation Expert Committee on Diabetes Mellitus (1980) Second report WHO Tech Rep Ser 646

16. Johansen K, Soeldner JS, Gleason RE (1974) Insulin, growth hormone, and glucagon in prediabetes mellitus - a review. Metabolism 23: 1185-1199

17. Srikanta S, Ganda OP, Gleason RE, Jackson RA, Soeldner JS, Eisenbarth GS (1984) Pre-Type 1 Diabetes: linear loss of beta cell response to intravenous glucose. Diabetes 33:717-720

18. Heaton DA, Millward BA, Gray P, Tun Y, Hales CN, Pyke DA, Leslie RDG (1987) Evidence of B-cell dysfunction which does not lead on to diabetes: a study of identical twins with insulin-dependent diabetes. Br Med J 294: 145-146

19. Millward BA, Alviggi L, Hoskins PJ, Johnston C, Heaton DA, Bottazzo GF, Vergani D, Leslie RDG, Pyke DA (1986) Immune changes associated with insulin dependent diabetes may remit without causing the disease: a study in identical twins. Br Med J 292: 793-796

20. Harris ML, Hadden WC, Knowler WC, Bennett PH (1987) Prevalence of diabetes and impaired glucose levels in US population aged 20-74. Diabetes 36: 523-534

21. McDonald GW, Fisher GF, Burnham C (1965) Reproducability of the oral glucose tolerance test. Diabetes 14: 473-480

Received: 15 November 1989

and in revised form: 23 March 1990

Dr. R.D.G.Leslie

Westminster Hospital

Horseferry Road

London SW1P 2AR

UK 